\title{
Transient middle cerebral artery occlusion in rats as an experimental model of brain ischemia $^{1}$
}

\author{
Modelo experimental de isquemia cerebral em ratos por obliteração temporária da artéria \\ cerebral média
}

\author{
Renato Luis Calloni', Bruno Costamilam Winkler"I, Guilherme Ricci" ${ }^{\mathrm{II}}$, Marcos Giacomelli Poletto", Wagner Martins Homero" \\ Eduardo Pretto Serafini ${ }^{\mathrm{III}}$, Oly Campos Corleta ${ }^{\mathrm{IV}}$
}

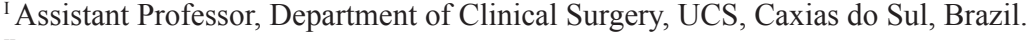

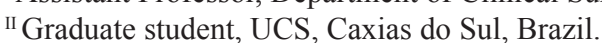 \\ III Full Professor, Department of Pathology, UCS, Caxias do Sul, Brazil. \\ ${ }^{\text {Iv }}$ Associate Substitute Professor, Department of Surgery, Federal University of Rio Grande do Sul (UFRGS), Porto Alegre, Brazil.
}

\begin{abstract}
Purpose: To assess a rat model of cerebral ischemia induced by occlusion of the middle cerebral artery and its effect on the area of cerebral infarction. Methods: Brain ischemia was induced in 52 male Wistar rats by introduction of a 3-0 nylon suture into the middle cerebral artery for either $90(n=28)$ or $120(n=24)$ minutes. Ischemic injury volume was determined by TTC staining, digital photography and analysis with the Image J software. Statistical analysis employed Student's $t$ test and the Mann-Whitney U test. Results: The groups were similar in terms of weight $(\mathrm{p}=0.59)$. The length of thread inserted was $14.7 \mathrm{~mm}$ in the 90 min group and $20.2 \mathrm{~mm}$ in the $120 \mathrm{~min}$ group ( $\mathrm{p}=0.37)$. Ischemic injury was detected in 11 animals $(39 \%)$ after $90 \mathrm{~min}$ and $11(45 \%)$ after $120 \mathrm{~min}(\mathrm{p}=0.77)$. In animals exhibiting injury, filament length was $16.1 \pm 11 \mathrm{~mm}(90 \mathrm{~min})$ vs. $21.9 \pm 7.4 \mathrm{~mm}(120 \mathrm{~min})(\mathrm{p}=0.15)$. The mean infarction zone volume was greater after $120\left(259.2 \mathrm{~mm}^{3}\right)$ than after $90 \mathrm{~min}\left(162.9 \mathrm{~mm}^{3}\right)(\mathrm{p}=0.04)$. The neurological deficit score for the 90 and $120 \mathrm{~min}$ groups was 2.0 and 2.4, respectively $(\mathrm{p}=0.84)$. Conclusion: The experimental model induced significant ischemic cerebral injury in both groups. Key words: Brain Ischemia. Infarction, Middle Cerebral Artery. Rats.
\end{abstract}

\section{RESUMO}

Objetivo: Avaliar o modelo de isquemia cerebral por oclusão da artéria cerebral média, mediante introdução de fio intraluminal por 90 e 120 minutos, e seu efeito sobre a área de infarto cerebral em ratos. Métodos: 52 ratos machos Wistar foram submetidos à isquemia cerebral por introdução de fio de nylon 3-0 na artéria cerebral média por 90 ou 120 minutos. O volume da lesão isquêmica foi determinado pelo corante TTC, fotografia digital e utilização do programa ImageJ. Na análise estatística, foi utilizado o teste $t$ - student e o U de Mann-Whitney. Resultados: O comprimento do fio introduzido foi de 14,7 mm no grupo 90 minutos e 20,2 mm no grupo 120 minutos. Lesão isquêmica foi detectada em 11 animais (39\%) no grupo que de 90 minutos e 11 (45\%) do grupo de 120 minutos. Nos animais que

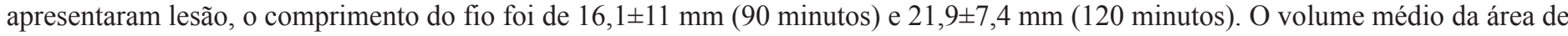
infarto foi maior no grupo 120 minutos do que no grupo 90 minutos. O escore de déficit neurológico foi de 2,0 no grupo 90 minutos e de 2,4 no grupo 120 minutos. Conclusão: O modelo experimental estudado induz lesão isquêmica cerebral significativa em ambos os grupos.

Descritores: Isquemia Encefálica. Infarto da Artéria Cerebral Média. Ratos.

${ }^{1}$ Research performed at Laboratory of Clinical Physiology, Faculty of Medicine, University of Caxias do Sul (UCS), Brazil.

\section{Introduction}

Cerebral infarction (stroke) is a significant cause of incapacity and disability in adults, in addition to exhibiting elevated rates of incidence and mortality ${ }^{1}$. During the acute phase of ischemia, the primary objective of treatment is to halt progression of the ischemic injury, with transformation of the ischemic penumbra into an area of infarction ${ }^{2}$.
Despite the technical advances that have been achieved in the treatment of brain ischemia, certain obstacles to its experimental evaluation still remain ${ }^{3}$. The length of time for which brain ischemia can be tolerated by the brain is dependent on the intensity of the ischemia, on the oxygen concentration in encephalic tissues, on primary and secondary metabolic reserves, on the velocity with which these reserves are consumed, on temperature and on the presence or absence of anesthetic drugs. 
Different areas of the brain have varying levels of vulnerability to ischemia. The prototype of focal brain ischemia that is most often employed is thrombosis due to middle cerebral artery occlusion (MCAO) ${ }^{4}$.

The use of animal models allows the pathophysiology of brain ischemia, particularly focal ischemia, to be studied and investigated $^{5}$. One of the most important contributions made by experimental models is to the evaluation of new therapeutic approaches $^{6}$.

The primary objective of this paper is to define an experimental model of brain ischemia in rats induced by middle cerebral artery occlusion, achieved by the intraluminal insertion of a suture thread for 90 minutes or for 120 minutes. Secondary objectives include assessment and comparison of the effects of middle cerebral artery occlusion by intravenous insertion of a suture for 90 and 120 minutes on the appearance of ischemic injuries, the magnitude of neurological deficit and the occurrence and volume of cerebral infarct.

\section{Methods}

The research protocol was approved by the Research Ethics Committee at the University of Caxias do Sul (UCS), RS, Brazil. Animals were cared for and procedures were carried out in accordance with the ethical standards for medical experimentation with animals described in the Guide for Care and Use of Laboratory Animals (National Academic Press, 1996).

Fifty-two adult male Wistar rats, with weight ranging from $300 \mathrm{~g}$ to $500 \mathrm{~g}$ and of similar ages were obtained from the animal house at the University of Pelotas, RS, Brazil. Animals were allocated to undergo arterial occlusion for $90 \mathrm{~min}$ (group A) or for $120 \mathrm{~min}$ (group B).

Anesthesia was induced using halothane in a bell jar. After sensory depression, intramuscular atropine was administered at a dosage of $5 \mathrm{mcg} / 100 \mathrm{~g}$ of body weight, and intramuscular tiletamine + zolazepam were given at doses of $0.18 \mathrm{ml}$ to $0.3 \mathrm{ml}$. Inspiratory air was enriched with $1 \mathrm{~L} / \mathrm{min}$ of $\mathrm{O}^{2}$ at $100 \%$ with a funnel.

Once the animal's anesthetic plan had been confirmed, it was placed on a support and immobilized with ties around its paws. After trichotomy of the cervical region, a longitudinal median cervical incision was made, of $2 \mathrm{~cm}$ to $3 \mathrm{~cm}$ in length, before proceeding to subcutaneous dissection to the vascular plane. The muscular planes and the trachea were retracted, and pulled laterally with elastic to facilitate exposure.

The surgical procedures were carried out with the aid of a surgical lens with 4 times magnification. The vagus nerve was dissected, separating it from the left common carotid artery (LCCA) (Figure 1). Vascular ligatures were performed using monofilament nylon thread 5-0. The left external carotid artery (LECA) was isolated and its branches: the superior thyroid artery and the lingual artery were joined. The occipital artery was coagulated using a surgical cauterizing machine and then sectioned. The LECA was sectioned at the bifurcation of its distal branches. The pterygopalatine artery, a branch of the internal carotid artery (ICA), was occlusion joined to the mastoid.

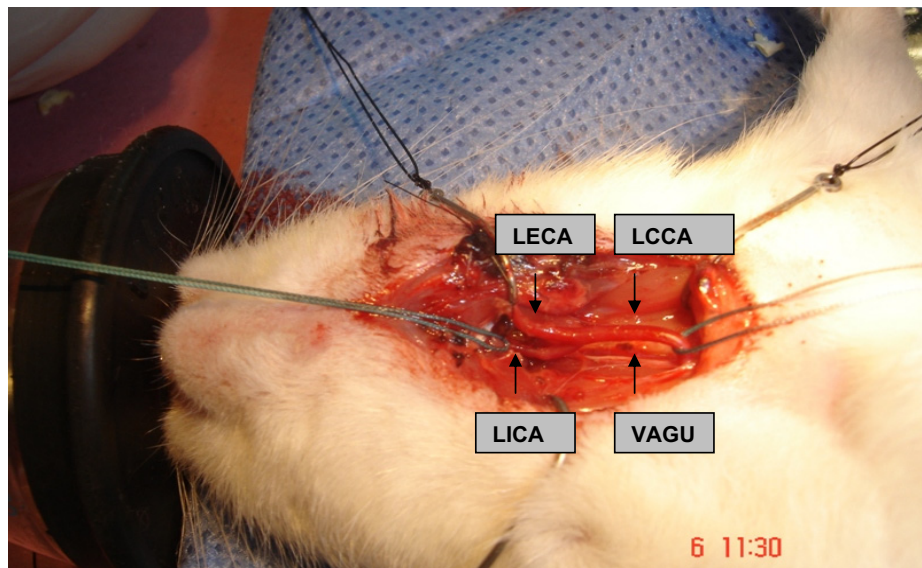

FIGURE 1 - Vascular anatomy of the carotid arteries and the vagus nerve of the rat. LECA = left external carotid artery; LCCA = left common carotid artery; LICA = left internal carotid artery; VAGUS = vagus nerve.

Temporary occlusion of the common carotid artery (CCA) and of the ICA was achieved using microclips, similar to those employed for cerebral aneurysm surgery. After arteriotomy at the proximal stump of the LECA, the occluding filament was introduced and the clip on the ACIE removed. The progression of the thread, from the bifurcation of the LCCA, was in the ascendant direction, via the ACIE lumen. The suture thread was introduced until it encountered firm resistance, when it was ligatured to the stump. The clip on the LCCA was released, and it was verified that blood flow had been reestablished. Any bleeding in the operating field was controlled. The operating incisions were then closed, in a single plane, using monofilament nylon thread 4-0. The thread chosen for occlusion was nylon monofilament 3-0. A $5 \mathrm{~cm}$ section was standardized to facilitate measurement of the length to be introduced. The tip that would be introduced was modified, rounding it off with heat (flame). The tip of the filament was moistened with synthetic balsam and left to dry.

After this initial procedure, the animals were returned to their cages and observed during the occlusion period until they were once more anesthetized in order for the occlusion to be removed. Once the occlusion period had elapsed, animals were anesthetized once more, with half of the initial doses. The sutures were removed, the incision reopened and the occluding filament withdrawn. Any bleeding from the LECA was coagulated. The incision was sutured once more. An injection of $10 \mathrm{ml}$ saline solution was given into the peritoneal cavity for hydration. Once the animals had woken up and exhibited spontaneous movement, they were assessed for presence and degree of neurological deficit, according to the of Gerriets et al. ${ }^{5}$ and Bederson et al. ${ }^{7}$ :

a) 0 - no neurological deficit;

b) 1 - failure to extend left forepaw fully;

c) 2 - inconstant circling to the left;

d) 3 - constant circling to the left;

e) 4 - falling to the left;

f) 5 - no spontaneous walking with depressed level of consciousness;

g) 6 - death. 
At the end of the procedure the rats were returned to their cages and given food and water ad libitum. After 24 hours had elapsed, the surviving animals were sacrificed by an overdose of anesthetic in a bell jar. The rats' brains were then removed and placed in cold water. They were sectioned in the coronal plane, producing five slices of $2 \mathrm{~mm}$ thickness which were stained in a 2\% 2.3.4-triphenyltretrazolium chloride (TTC) solution. The slices were incubated for 30 minutes at $37^{\circ} \mathrm{C}$ in buffered formalin solution at $10 \%$. They were then stored at $-4^{\circ} \mathrm{C}$ for $24 \mathrm{~h}$, in a sealed container with no exposure to light ${ }^{7}$. The slices were then photographed for later measurement and analysis of the infarct, using a Sony camera with 3.2 Megapixel resolution. The infarct volume was measured using the NIH IMAGE J 1.31 software for Windows. The areas of infarct on each slice were measured and their area multiplied by the thickness of $2 \mathrm{~mm}$ to arrive at the volume of the infarct zone. Analysis and measurement of the infarct zone was carried out by an investigator who was blind to the procedure. Measurements were in pixels, and area was then calculated in $\mathrm{mm}^{2}$ and mean volume in $\mathrm{mm}^{3}$ (Figure 2).

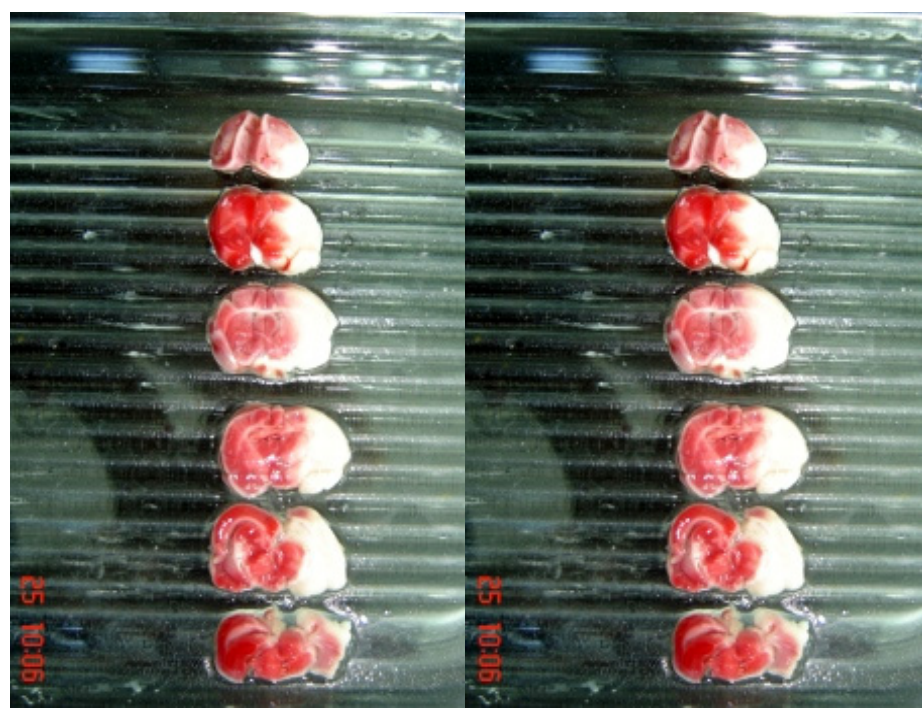

FIGURE 2 - Specimens stained with TTC, demonstrating ischemic injury.

All of the data measured were collected in isolation and both the infarct zone and the unaffected zones were measured.

\section{Statistical analysis}

Quantitative data were described using means and standard deviations, and categorical data are presented as frequencies and percentages. Quantitative data were compared between groups using Student's $t$ test for independent samples. Where data were asymmetrical, the Mann Whitney U test was applied for comparative analysis. The Mann Whitney U test was also used to compare neurological examination results. The categorical variables, injuries and weight, were compared using Fischer's exact test. Analysis of covariance was employed in order to adjust the comparison of mean ischemic area and volume between groups for the potential confounding factor of weight. The level of significance adopted for this study was $\infty=0.05$.

Data were processed and analyzed using the software program SPSS, version 12.0.

\section{Results}

The main results concerning the study variables are presented in Table 1. Table 2 shows the presence of injury according to duration of occlusion.

There was no statistically significant difference between the groups in relation to weight $(p=0.59)$. The length of the filament introduced was $14.6 \pm 9 \mathrm{~mm}$ in group $\mathrm{A}(90$ minutes, $\mathrm{n}=28)$ and $20.2 \pm 8 \mathrm{~mm}$ in group $\mathrm{B}$ (120 minutes, $\mathrm{n}=24)$. A greater length of filament was introduced into animals in group $\mathrm{A}(\mathrm{p}=0.04)$.

TABLE 1 - Results of study variables by group

\begin{tabular}{|c|c|c|c|}
\hline & Group A & Group B & p \\
\hline Weight(Grams) & N23 \pm 41 & $439 \pm 46$ & 0.59 \\
\hline Time in surgery & $64.8 \pm 41$ & $66.04 \pm 22$ & 0.82 \\
\hline Filament length $(\mathbf{m m})$ & $14.6 \pm 9.8$ & $20.1 \pm 8.4$ & 0.04 \\
\hline N.S. & $2.0 \pm 1.1$ & $2.4 \pm 0.6$ & 0.19 \\
\hline IsVol (mm $)$ & $162.9 \pm 110.8$ & $259.3 \pm 125.1$ & 0.13 \\
\hline mIsA $\left(\mathrm{mm}^{2}\right)$ & $12.4 \pm 7.6$ & $18.5 \pm 9.4$ & 0.25 \\
\hline
\end{tabular}

Weight $=$ grams

Filament $\mathrm{mm}=$ length of suture filament, measured from the carotid bifurcation.

N.S. = neurological score.

Is Vol $\mathrm{mm}^{3}=$ volume of ischemic area in $\mathrm{mm}^{3}$.

$\mathrm{mIsA}=$ mean ischemic area

TABLE 2 - Animals with and without injury, by duration of occlusion

\begin{tabular}{|c|c|c|}
\hline & Uninjured & Injured \\
\hline $\mathbf{9 0}$ min & 60.7 & 39.3 \\
\hline $\mathbf{1 2 0} \mathbf{~ m i n}$ & $\mathrm{n} 17$ & $\mathrm{n} 11$ \\
\hline $\mathbf{n} \mathbf{2 4}$ & $\mathrm{n} 13$ & $\mathrm{n} 11$ \\
\hline
\end{tabular}


Ischemia was observed in 11 animals (40\%) in group A and in $11(50 \%)$ in group B. There was no statistically significant difference between the groups, with relation to occurrence of ischemia $(p=0.78)$. The risk in group A was $1.07(95 \%$ CI $0.65-1.76)$ and in group B it was 0.97 (95\% CI 0.52-1.68).

The mean percentage of total brain volume that was ischemic in group A $(n=11)$ was $12.4 \pm 7.6 \%$ and in group B it was $18.4 \pm 9.4 \%$. Group B exhibited the larger ischemic area $(\mathrm{p}=0.05)$.

The volume calculated for the ischemic area in group A $(\mathrm{n}=11)$ was $162.9 \pm 111.0 \mathrm{~mm}^{3}$ vs. $259.2 \pm 125.1 \mathrm{~mm}^{3}$ in group $\mathrm{B}$ $(n=11)$ (Figure 3). There was no statistically significant difference between the groups with relation to infarct volume $(p=0.07)$. However, statistical significance was reached after analysis of covariance was applied to adjust mean infarct volume by the body weight of each animal (group $A=162.9 \pm 111.0 \mathrm{~mm}^{3}$ vs. group $\mathrm{B}$ $\left.259.2 \pm 125.1 \mathrm{~mm}^{3}\right)(\mathrm{p}=0.04)$.

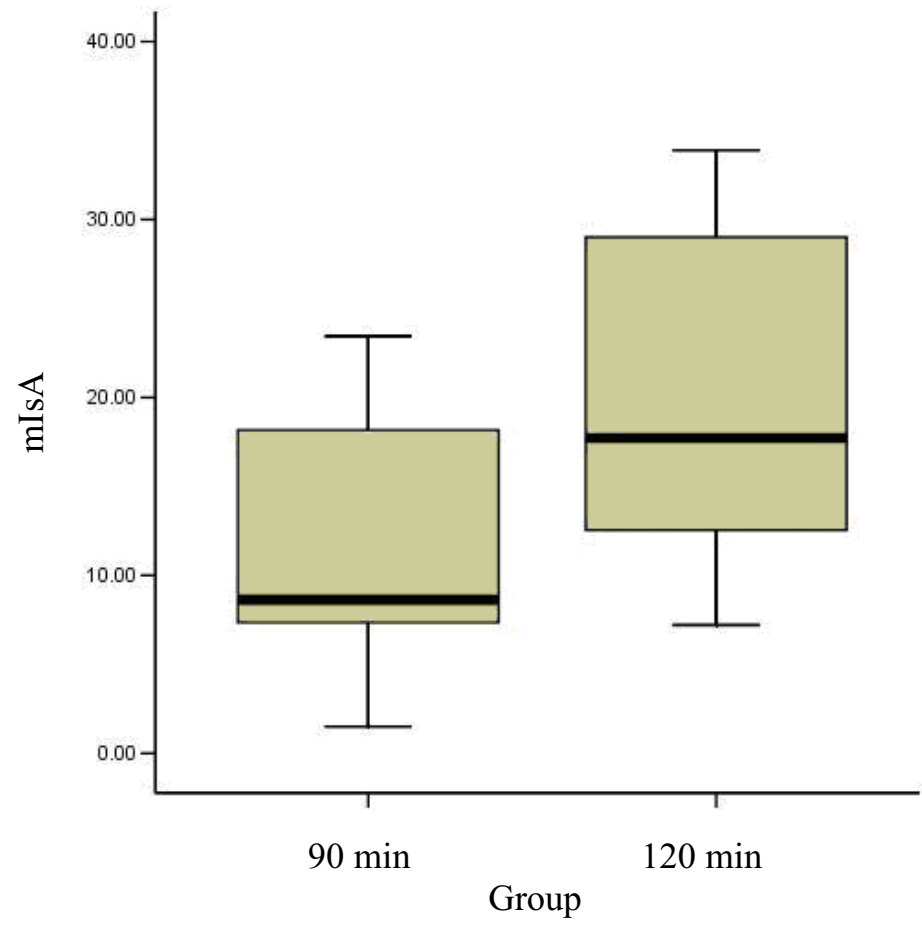

FIGURE 3 - Mean ischemic area with relation to percentage and distribution within groups. $\mathrm{mIsA}=$ mean ischemic area.

The neurological examination scores are shown in Table 3. None of the animals scored 0 or 4 ; 1 animal scored 1 (4.5\%); 12 scored $2(54.5 \%)$ and 9 scored $3(40.9 \%)$. Group A had a mean score of $2.04 \pm 1.1$, while group B had a mean of $2.38 \pm 0.5(p=0.65)$.
TABLE 3 - Distribution of neurological scores by duration of occlusion

\begin{tabular}{|c|c|c|c|c|}
\hline & $90 \mathrm{~min}$ & $\mathrm{~N}$ & $120 \mathrm{~min}$ & $\mathrm{n}$ \\
\hline 0 & 7.1 & 2 & 0 & \\
\hline 1 & 25.0 & 8 & 0 & \\
\hline 2 & 30.4 & 7 & 66.6 & 16 \\
\hline 3 & 32.0 & 9 & 29.2 & 7 \\
\hline 4 & 7.1 & 2 & 3.3 & 1 \\
\hline
\end{tabular}

Figures in percentage $\%$. $\mathrm{p}=0.26$

\section{Discussion}

A diversity of techniques for inducing brain ischemia has been described, which causes heterogeneous results and makes comparisons difficult. The methods that have been described employ approaches via craniotomy, for arterial occlusion or embolization; or via cervicotomy, for occlusion of three or four vessels ${ }^{1-8}$. Experimental occlusion of the middle cerebral artery (MCAO) is the method most often used in research to obtain focal brain ischemia ${ }^{4}$. The variations in duration of ischemia have also contributed to the diversity of experimental research models ${ }^{1}$.

The Longa et al. ${ }^{9}$ method consists of introducing surgical thread into the internal carotid artery (ICA), progressively, until the middle cerebral artery (ACM) is occluded. Cerebral infarction is achieved in $56 \%$ of cases, and the mortality rate is significant. Removal of the occluding thread removes the obstruction, which leads to reperfusion of the ischemic tissues ${ }^{9}$. This mimics the conditions that occur during current treatment of an ischemic vascular accident, which aims to remove the vascular obstruction by means of angioplasty or thrombolysis. Furthermore, this method allows the consequences of different durations of ischemia to be studied. The use of monofilament nylon thread 3-0 covered in poly-1-lysine, a glue, induces higher rates of cerebral infarction ${ }^{10}$. Factors that limit the success of this experiment may be related to the fact that the tip of the filament cannot be seen. If it is not secured in the correct position, at the origin of the ACM, immediately distal of its bifurcation from the ICA, premature reperfusion or malocclusion of the ACM may occur. It has also been reported that the filament may be displaced by increased arterial blood pressure during the experiment ${ }^{11}$. If the occluding filament does not progress far enough into the ICA, it will only occlude the anterior choroidal artery, which originates at the intracranial portion of the ICA and not from the ACM, which sets up collateral flow via the opposite side, through the ipsilateral ACA and ICA bifurcation ${ }^{5,6}$. 
Other factors that can interfere with the occurrence of the cerebral infarction in this model are: variations in ACM length, anatomic variation in its branches, and substitution of collateral branches ${ }^{12}$. The experience of the researcher is also an important factor in application of this method. The perception of resistance to the thread's progress is to a great extent subjective, dependent on training ${ }^{11}$.

Questions continue to be asked in the literature about the choice of thread for occlusion ${ }^{12}$. The filament diameter and composition are critical factors in obtaining results from the MCAO model ${ }^{13}$. The diameter chosen for this study, 3-0, allows better occlusion and induces stroke with greater consistency and duration? .

The use of glue provides better adherence, which, theoretically, increases the chances of causing ischemic injury?. There is a relationship between the length of the thread introduced into the ICA and the presence of neurological deficit. The length of the filament inserted to cause MCAO varies, according to several authors, from $17 \mathrm{~mm}$ to $23 \mathrm{~mm}$, depending on the breed and weight of rat ${ }^{9,10,14,15}$. The introduction of a section of thread of $22 \mathrm{~mm}$ or longer provokes greater neurological deficits when compared with the introduction of $18 \mathrm{~mm}^{16}$. Zhao et al. ${ }^{17}$ has shown that the length of thread varies according to the weight of the animal.

Kaplan et al. ${ }^{18}$ found that reestablishing perfusion 1 hour after induction of ischemia may not result in significant cerebral infarction. Ischemia sustained for between 1 and 2 hours is sufficient to cause infarction, whereas, after 3 hours, the resulting infarct is no different to that obtained with complete occlusion. This statement corroborates the results of Longa et al. ${ }^{9}$ according to which occlusion for more than 2 hours does not increase the area of infarction and is similar to the results of permanent occlusion.

A study performed using magnetic resonance imaging, during the acute phase of ischemia, demonstrated that abnormal diffusion volume increases during the first 90 minutes and reaches its peak after 2 hours, suggesting that this is the time taken for irreversible tissue damage to set $\mathrm{in}^{2}$. The formation of edema and its rapid fall are characteristic of reperfusion models. The edema influences the formation and increase of the infarct, and therefore the time taken for output to improve is related to the time taken for the edema to reduce ${ }^{19}$.

Engelhorn et $a l .{ }^{20}$ have observed that one hour after MCAO reperfusion significantly reduced the infarct volume and improved neurological results significantly when compared with the study's controls. There was no reduction in the infarct area, when occlusion lasted longer than 2 hours. It should be mentioned that the Wistar breed is known to exhibit tolerance to periods of MCAO of more than 120 minutes and exhibits good survival rates ${ }^{21}$.

The dimension is of the infarct zone have frequently been used as a primary indicator of the extension of cerebral ischemic damage in animal models. The infarction volume can be identified by histochemical methods, such as those employed in the study, through the use of triphenyltretrazolium chloride (TTC) ${ }^{7,9,22}$. There is evidence that when injuries are measured by TTC they appear smaller than with magnetic resonance imaging, probably due to the influence of tissue edema ${ }^{3-24}$. These results are in agreement with those presented by Takano et al. ${ }^{23}$, who compared data from a novice researcher $\left(195.9 \mathrm{~mm}^{3}\right)$, one with experience $\left(212.6 \mathrm{~mm}^{3}\right)$ and a very skilled researcher $\left(204.7 \mathrm{~mm}^{3}\right)^{23}$. Results within a similar range were found by Dogan et al..$^{24}$ comparing hypertensive rats $\left(262.6 \mathrm{~mm}^{3}\right)$ with rats with normal pressure $\left(145.4 \mathrm{~mm}^{3}\right)$ after MCAO and also by Zhao et al. ${ }^{17}$, who observed $149 \mathrm{~mm}^{3}$.

Gerriets et al. ${ }^{12}$ studied the percentage of brain affected by infarct and related it to duration of ischemia, obtaining $29.8 \%$ in 30 minutes and $46.8 \%$ in 240 minutes $^{5}$. Yang et al. ${ }^{12}$ achieved $27.6 \%$.

Absence of motor deficits may indicate a failed occlusion and, therefore, failure to apply the method. It is not possible to identify these animals based merely on clinical examination, since they may exhibit signs of deficits irrespective of occlusion of the cerebral artery ${ }^{6-11}$. The neurological score is not completely reliable, since signs and behaviors are dependent on some parts of the infarct site and are not part of the assessment ${ }^{25}$.

\section{Conclusions}

The experimental of brain ischemia, induced by occlusion of the middle cerebral artery by intraluminal filament proved viable under our laboratory and technical conditions. Its use offers promising prospects for carrying out future projects, especially in studies of treatments using stem cells.

\section{References}

1. Carmichael TS. Rodent models of focal stroke: size, mechanism, and purpose. NeuroRx. 2005;2:396-409.

2. Henninger N. Comparisons of ischemic lesion evolution in embolic versus mechanical middle cerebral artery occlusion in Sprague Dawley rats using diffusion and perfusion imaging. Stroke. 2006;37:1283-7.

3. Bardutzki J, Shen Q, Henninger N, Bouley J, Duongt Q, Fischer M. Differences in ischemic lesions evolution in different strain using diffusion and perfusion imaging. Stroke. 2005;36:2000-5.

4. Hossmann KA. Experimental models for the investigation of brain ischemia. Cardiovasc Res. 1998;39:106-20.

5. Gerriets T, Stolz E, Walberer M, Müller C, Rottger C, Kluge A, Kaps M, Fischer M, Bachmann G. Complications and pitfalls in rat stroke models for middle cerebral artery occlusion: a comparison between the suture and macro sphere model using magnetic resonance angiography. Stroke. 2004;35:2372-7.

6. Dittmar M, Spruss T, Schuierer G, Horn M. External carotid artery territory ischemia impairs outcome in the endovascular filament model of middle cerebral artery occlusion in rats. Stroke. 2003;34:2252-7.

7. Bederson JB, Pitts LH, Tsuji M, Nishimura MC, Davis RL, Bartkowski H. Rat middle cerebral artery occlusion: evaluation of model and development of a neurologic examination. Stroke. 1986;17:472-6.

8. Koizumi J, Yoshida Y, Nakazawa T, Ooneda G. Experimental studies of ischemic brain edema. I: a new experimental model of cerebral embolism in rats in which recirculation can be introduced in the ischemic area. Jpn J Stroke. 1986;8:1-8.

9. Longa EZ, Weinstein PR, Carlson S, Cummins R. Reversible middle cerebral artery occlusion without craniotomy in rats. Stroke. 1989;20:84-91. 
10. Belayev L, Alonso OF, Busto R, Zhao R, Ginsberg MD. Middle cerebral artery occlusion in the rat by intraluminal suture. Stroke. 1996;27:1616-22.

11. Sun F, Lopez-Sanches C, Romero FJM, Luis L, Merino CG, Martinez VG. Transfemoral selective "intraluminal wiring" technique for transient middle cerebral artery occlusion in rats. J Neurosci Methods. 2005;149:82-9. 12. Yang Y, Yang T, Li Q, Wang CX, Shuaib A. A new reproducible focal cerebral ischemia model by introduction of polyvinylsiloxane into middle cerebral artery: a comparison study. J Neurosci Methods. 2002;118:199-206. 13. Kuge Y, Minematsu K, Yamaguchi T, Miyake Y. Nylon monofilament for intraluminal middle cerebral artery occlusion in rats. Stroke. 1995;26:1655-7.

14. Ábrahám H, Somogyvári-Vigh A, Maderdrut Jl, Vihg S, Arimura A. Filament size influences temperature changes and brain damage following middle cerebral artery occlusion in rats. Exp Brain Res. 2002;142:131-8. 15. Forsting M, Reith W, Schäbitz W, Heiland S, Kummer R Von, Hacke W, Sartor K. Decompressive craniectomy for cerebral infarction. Stroke. 1995;26:259-64.

16. Schimid-Elsaesser R, Zausinger S, Hungerhuber E, Baethmann A, Reulen H-J. Monotherapy with dextromethorphan or trilazard-but not a combination of both: improves outcome after transient focal cerebral ischemia in rats. Exp Brain Res. 1998;122:1-127.

17. Zhao W, Ginsberg M, Prado R, Belayev L. Depiction of infarct frequency distribution by computer-assisted image mapping in rat brains with middle cerebral artery occlusion. Comparison of photothrombotic and intraluminal suture models. Stroke. 1996;27:1112-7.
18. Kaplan B, Brint S, Tanabe J, Jacewicz M, Wang XJ, Pulsinelli W. Temporal threshold for neocortical infarction in rats: subjected to reversible focal cerebral ischemia. Stroke. 1991;22:1032-9.

19. Takamatsu H, Tatsumi, M, Nitta S, Ichise R, Muramatsu K, Iida M, Nishimura S, Umemura K. Time course of progress to the chronic stage of middle cerebral artery occlusion models in rats. Exp Brain Res 2002;46:95-102.

20. Engelhorn T, Kummer R Von, Reith W, Forsting M, Doerfler A. What is effective in malignant middle cerebral artery? Infarction: reperfusion, craniectomy, or both? An experimental study in rats. Stroke. 2002;33:617-22. 21. Peeling J, Corbett D, Del Bigio MR, Hudzik TJ, Campbell M, Palmer GC. Rat middle cerebral artery occlusion correlations between histopathology, T2-weighted magnetic resonance imaging, and behavioral indices. J Stroke Cerebrovasc Dis. 2001;10:166-77.

22. Schilichting CRL, Cestari Junior LA, Sekiyama JY, Silva FM, Milani $\mathrm{H}$. Validation of a simple and inexpensive method for the quantitation of infarct in the rat brain. Braz J Med Biol Res. 2004;37:511-21.

23. Takano K, Tatlisumak T, Bergmann AG, Gibson DG, Fischer M. Reproducibility and reliability of middle cerebral artery occlusion using a silicone-coated suture in rats. J Neurol Sci. 1997;153:8-11.

24. Dogan A, Baskaya MK, Rao VL, Rao AM, Dempey RJ. Intraluminal suture occlusion of the middle cerebral artery in spontaneously hypertensive rats. Neurol Res. 1998;20:265-7.

25. Roof RL, Schielke GP, Ren X, Hall ED. A comparison of long-term functional outcome after 2 middle cerebral artery occlusion models in rats. Stroke. 2001;32:2648-57.

\section{Correspondence:}

Dr. Renato Luis Calloni

R. São Salvador, 177

95050-430 Caxias do Sul - RS Brasil

rcalloni@terra.com.br

Conflict of interest: none

Financial source: none

Received: February 09, 2010

Review: April 12, 2010

Accepted: May 18, 2010

\section{How to cite this article}

Calloni RL, Winkler BC, Ricci G, Poletto MG, Homero WM, Serafini EP, Corleta OC. Transient middle cerebral artery occlusion in rats as an experimental model of brain ischemia. Acta Cir Bras. [serial on the Internet] 2010 Sept-Oct;25(5). Available from URL: http://www.scielo.br/acb

*Color figures available from www.scielo.br/acb 